\title{
SISTEM INFORMASI AKUNTANSI PERSEDIAAN MATERIALBERBASIS WEB MENGGUNAKAN METODE FIFO (First In First Out) (Studi Kasus Pada PT. Teknik Bina Mandiri Cikarang)
}

\author{
${ }^{1}$ Feni Untari, ${ }^{2}$ Wawan Kusdiawan, ${ }^{3}$ Dedi Supriadi \\ E-mail : ${ }^{1}$ feniuntari14@gmail.com, ${ }^{2}$ wawankusdiawan8@gmail.com dan \\ dedidevan9@gmail.com
}

\begin{abstract}
Abstrak
PT. Teknik Bina Mandiri (PT. TBM) merupakan perusahaan yang bergerak dibidang mesin bubut yang memproduksi tool \& die, precision-parts, engginering, dan general supplier yang beralamat di Jl. Tarum Barat. I No.83, Jayamukti, Cikarang Pusat, Bekasi, Jawa Barat 17530. PT. Teknik Bina Mandiri sendiri mempunyai stok material yaag lumayan banyak dan tidak dapat bertahan lama seperti baja, logam, dan besi yang besar kemungkinan rentang akan karat dan penggunaan material untuk produksi sangat tidak teratur sehingga mengakibatkan pembelian material sering dilakukan dan mengakibatkan pengeluaran biaya pembelian material meningkat. Di bagian gudang juga banyak terdapat material yang dibeli sudah lama tapi belum terproses sehigga mengakibatkan penumpukan material berkarat. Dalam pengolahan persediaan juga sering mengalami keterlambatan pembelian material. Untuk itu dibutuhkan sistem yang diharapkan dapat membantu masalah yang terjadi didalam perusahaan tersebut. Terkait hal itu, maka dibuat sistem persediaan material berbasis web dengan menggunakan metode FIFO (first in first out) menggunakan bahasa pemograman PHP. Dalam analisa pembutan sistem menggunakan metode SDLC (System Development Life Cycle) dan menggunakan sistem OOA (Object Oriented Aproach) untuk mempermudah analisa dalam pembuatan sistem.
\end{abstract}

Kata Kunci: FIFO, OOA, Sistem, Informasi, Material

\begin{abstract}
PT. Bina Mandiri Engineering (PT TBM) is a company engaged in lathes that produce tools \& dies, precision-parts, engginering, and general suppliers are located at jl. Tarum Barat. I am No.83, Jayamukti, Cikarang Pusat, Bekasi, Jawa Barat 17530. PT. Bina Mandiri's own technique has quite a lot of stock material and can not be left old like steel, metal, and iron that will be widely used and materials used for production is not very appropriate. In the warehouse is also a lot of material that has long but not yet processed sehigga related to the buildup of rusty materials. In processing also often occurs material purchase. For that needed a system that can help problems that occur within the company. Related to that, then made a web-based materials preparation system using FIFO method (first in first out) using PHP programming language. In the system pembutan analysis using SDLC (System Development Life Cycle) and using the system OOA (Object Oriented Aproach) to facilitate the analysis in the manufacture of the system.
\end{abstract}

Keywords: FIFO, OOA, System, Information, Material 


\section{Pendahuluan}

Sistem informasi akuntansi persediaan material merupakan hal yang penting bagi suatu perusahaan dagang. Penulis melakukan penelitian tentang persediaan material pada PT.Teknik Bina Mandiri menurut penelitian dari Lois Raymond, Anne-Marie Croteau, dan Francis Bergeron dalam The Strategic Role of IT as an Antecedent to the IT Sophistication and IT Performance of Manufacturing SMEs, Volume 4, No. 3 \& 4, 2011 (p,203): "Now, IT can play an important role in a company's performance and its ability to respond effectively to the changing needs of the market."Artinya, Saat ini teknologi informasi memiliki peran penting bagi kinerja dan kemampuan perusahaan agar dapat menanggapi perubahan kebutuhan pasar secara efektif. Pada bagian gudang tidak terdapat sistem pencatatan material. Bagian PPIC/admin harus turun langsung ke gudang untuk memastikan bahwa material yang akan diproduksi masih tersedia atau tidak, dan memeriksa material apa saja yang harus dibeli. Belum adanya laporan yang terkait dengan persediaan seperti tidak adanya laporan barang masuk dan laporan barang keluar. Laporan persediaan akan sangat menyulitkan pimpinan untuk membuat keputusan.

Menurut penelitian dari Siamak Nejadhosseini Soudani dalam The Usefulness of an Accounting Information System for Effective Organizational Performance, Volume 4, No. 5 2012 (p137): "Information is available data processing that provides a basis for making decision and taking action. "Artinya , Informasi merupakan data hasil pemrosesan yang bernilai dan mampu menyediakan dasar bagi pembuat keputusan dan mengambil tindakan.

Perusahaan dalam setiap persediaan mempunyai peranan penting dalam menentukan biaya atau menentukan nilai barang untuk dijadikan patokan menentukan harga pokok produksi barang yang akan dijual. Begitu pentingnya perananan persediaan dalam operasional perusahaan sehingga perlu diterapkan metode untuk menentukan harga pokok persediaan yaitu metode identifikasi khusus, metode pertama kali masuk pertama keluar (FIFO), metode terakhir masuk pertama keluar (LIFO) dan metode rata-rata (Weight Average Cost). PT. Teknik Bina Mandiri sendiri mempunyai stok material yaag lumayan banyak dan tidak dapat bertahan lama seperti baja, logam, dan besi yang rentang akan karat dan penggunaan material untuk produksi sangat tidak teratur sehingga mengakibatkan pembelian material sering dilakukan dan mengakibatkan pengeluaran biaya pembelian material meningkat. Dalam pengolahan persediaan juga sering mengalami keterlambatan pembelian material karena tidak ada pengawasan terhadap persediaan di gudang. Untuk itu dibutuhkan sistem yang diharapkan dapat membantu masalah yang terjadi didalam perusahaan tersebut.

Berdasarkan uraian dari permasalahan diatas maka dibutuhkan suatu aplikasi pengolahan data yang dilakukan secara efisien yang mampu mengelola persediaan material untuk membantu permasalahan yang terjadi di dalam perusahaan. oleh karena itu penulis membangun sistem informasi berbasis web dengan menggunakan metode FIFO (First In First Out) dengan bahasa pemograman PHP. Dalam pembuatan aplikasi Sistem Informasi Persediaan Material ini, penulis menggunakan model analisis dengan pendekatan Object Oriented Approach dan dalam analisis data menggunakan metode SDLC (System Development Life Cycle) Dengan demikian penulis membangun sebuah sistem yang berjudul "Sistem Informasi Persediaan Material Berbasis Web Menggunakan Metode FIFO (First In First Out) Studi Kasus Pada PT. Teknik Bina Mandiri Cikarang”.

\section{TinjauanPustaka}

\section{Pengertian Sistem}

Sistem adalah suatu jaringan kerja dari prosedur-prosedur yang saling berhubungan, berkumpul bersama-sama untuk melakukan suatu kegiatan atau untuk menyelesaikan suatu sasaran yang tertentu. Suatu sistem memiliki karakteristik atau sifat-sifat tertentu yaitu komponen sistem, batas sistem, lingkungan luar sistem, penghubung sistem, masukan sistem, 
keluaran sistem, pengolah sistem, dan sasaran sistem. (Jogiyanto., 2009:1)

\section{Pengertian Informasi}

Menurut Wing Wahyu Winarno (2006:16), "Informasi adalah data yang sudah diolah sehingga berguna untuk pembuatan keputusan". Kualitas dari suatu informasi tergantung dari 3 hal, yaitu informasi harus akurat, tepat waktu, dan relevan

Karakteristik Informasi:

a) Akurat

Menggambarkan kondisi objek yang sesungguhnya.

b) Tepat waktu

Informasi harus tersedia sebelum keputusan dibuat. Seringkali informasi tidak diperlukan lagi setelah keputusan dibuat.

c) Lengkap

Mencakup semua yang diperlukan oleh pembuat keputusan. Lengkap tidak berarti memberi semua informasi..

d) Relevan

Berhubungan dengan keputusan yang akan diambil. Keputusan mengenai penagihan utang, hanya memerlukan informasi tentang transaksi yang menimbukan utang (tanggal,jumlah transaksi). Kualitas informasi ini sangat berhubungan dengan "lengkap".

e) Terpecaya

Isi informasi dapat dipercaya (istilah lainnya reliable). Hal ini tergantung kepada pemberi informasi. Misal, program komputer di suatu perusahaan mengandung kesalahan, sehingga informasi yang disajikan sering keliru. Lama kelamaan, pemakai informasi akan tahu bahwa output program tidak dapat dipercaya.

f) Terverifikasi

Dapat dilacak ke sumber aslinya (veriable). Apabila pemakai laporan tidak yakin dengan informasi yang diterimanya, dia ingin mendapatkan sumber informasi yang diperolehnya, untuk memeriksa apakah benar informasi yang telah diterimanya itu.

g) Mudah dipahami
Informasi harus siap dipahami oleh pembacanya. Pemakai laporan tidak ingin berfikir lagi dalam menerima informasi, dia hanya ingin tahu kesimpulannya saja, apakah informasi yang diperlukannya benar (apakah perusahaan laba, kalau ya berapa, dia tidak ingin tahu penjualan tunai berapa, piutang berapa, barang terjual, dsb).

h) Mudah diperoleh

Informasi yang sulit diperoleh bisa tidak berguna. Pemakai tidak ingin bersusah payah mencari informasi. Bahkan, bila perlu dia tidak perlu membaca informasi agar tahu isinya, misalnya saja dalam bentuk grafik atau suara atau warna

\section{Pengertian Akuntansi}

Menurut Wing Wahyu Winarno (2006:18), "akuntansi adalah proses mencatat dan mengolah data transaksi dan menyajikan informasi kepada pihak-pihak yang berhak dan berkepentingan".

\section{Pengertian Sistem Inforamsi Akuntansi}

Menurut Azhar Susanto (2013:72) dalam bukunya yang berjudul "Sistem Informasi Akuntansi yang dimaksud adalah kumpulan atau group dari sub sistem atau bagian atau komponen apapun baik fisik atau no fisik yang saling berhubungan satu sama lain dan bekerja sama secara harmonis untuk mengolah data transaksi yang berkaitan dengan masalah keuangan menjadi informasi keuangan".

\section{Pengertian Persediaan}

Persediaan adalah rangkaian kegiatan produksi dan distribusi ini mulai dari pembelian bahan baku, terus produksi melalui semua kegiatan operasi dalam pabrik sampai di gudang barang jadi dan dari gudang barang jadi ini terus ke tempat-tempat distribusi sampai akhirnya pada konsumen yang terakhir. (2016 : Makalah Online). Persediaan adalah aktiva yang dimiliki perusahaan untuk dijual dalam operasi bisnis atau barang yang akan digunakan untuk digunakan dalam pembuatan produk perusahaan yang akan dijual. Pentingnya persediaan barang dalam perusahaan biasanya diperlukan untuk memenuhi kebutuhan produksi sebuah perusahaan untuk mempermudah proses produksi. Oleh karen itu perusahaan harusnya mempunyai pengawasan dalam persediaan 
barang ,karena persediaan merupakan aktiva yang menyangkut dalam aset yang dimiliki oleh perusahaan dan akan berpengaruh dalam laporan keuangan.

\section{Metode Persediaan}

Beberapa metode penilaian persediaan yang ada dapat diuraikan sebagai berikut :

a. Metode Identifikasi Khusus

Metode harga pokok yang didasarkan atas metode identifikasi khusus adalah suatu metode penilaian harga yang didasarkan atas nilai perolehan dari barang yang sesungguhnya. Penggunaan metode ini biasanya dipakai untuk barang yang tidak banyak unitnya (kuantitasnya) dan harganya pun cukup mahal.

1) Metode Rata-rata (Average Method) Metode harga pokok rata-rata adalah suatu metode penilaian persediaan yang didasari atas harga rata-rata dalam periode yang bersangkutan. Besar kecilnya nilai persediaan yang masih ada dan harga pokok barang yang dijual, dipengaruhi oleh metode yang dipakai dalam metode rata-rata adalah :

1) Sistem fisik yang dibagi menjadi metode rata-rata sederhana dan metode rata-rata tertimbang.

2) Sistem perpetual (metode rata-rata bergerak). Rumus yang digunakan pada metode rata-rata adalah sebagai berikut :

- Metode rata-rata sederhana :

Biaya perunit $=$ Total harga perunit pembelian Frekuensi pembelian

Nilai persediaan akhir = Persediaan akhir $\mathrm{x}$ biaya perunit Harga pokok penjualan $=$ unit yang dikeluarkan $\mathrm{x}$ biaya perunit.

- Metode rata-rata tertimbang: Biaya perunit $=$ Jumlah harga perunit $x$ banyaknya unit Banyaknya Unit

Nilai persediaan akhir $=$ persediaan akhir $\mathrm{x}$ biaya perunit

Harga pokok penjualan = unit yang dikeluarkan $\mathrm{x}$ biaya perunit.
- Metode rata-rata bergerak :

Metode ini diselenggarakan dengan kartu persediaan dan harga pokok perunit persediaan selalu berubah setiap terjadi pembelian barang baru. Harga pokok rata-rata = harga perolehan lama + harga perolehan baru Unit barang lama + unit barang baru.

\section{2) Metode Masuk Pertama Keluar Pertama (First In First Out)}

Metode First In First Out (FIFO) adalah metode penilaian persediaan yang menganggap barang yang pertama kali masuk diasumsikan keluar pertama kali pula. Pada umumnya perusahaan menggunakan metode ini, sebab metode ini perhitungannya sangat sederhana baik sistem fisik maupun sistem perpetual akan menghasilkan penilaian persediaan yang sama.

Cara menghitung persediaan akhir adalah sebagai berikut :

$\begin{array}{ll}\text { Persediaan awal } & \mathrm{xxx} \\ \text { Pembelian } & \mathrm{xxx}+ \\ \text { Tersedia untuk dijual } & \mathrm{xxx} \\ \text { Penjualan } & \mathrm{xxx}- \\ \text { Persediaan akhir } & \mathrm{xxx}\end{array}$

Metode FIFO yang didasarkan atas sistem fisik, nilai persediaan akhir ditentukan dengan cara saldo fisik yang ada dikalikan harga pokok perunit barang yang terakhir kali masuk, bila saldo fisik ternyata lebih besar dari jumlah unit terakhir masuk maka sisanya diambilkan dari harga pokok perunit yang masuk sebelumnya. Sedangkan pada sistem perpetual pencatatan persediaan dilakukan secara terus menerus dalam kartu persediaan. Pada sistem ini apabila ada transaksi penjualan maka akan dijurnal dua kali, pertama mencatat harga pokok penjualan dan yang kedua mencatat harga pokok barang yang dijual, seperti berikut ini :

Kas/ Piutang Dagang xxx 


$\begin{array}{ll}\text { Penjualan } & \mathrm{xxx} \\ \text { HPP } & \mathrm{xxx} \\ \text { Persediaan barang } & \mathrm{xxx}\end{array}$

\section{3) Metode Masuk Terakhir Keluar Pertama (Last In First Out)}

Metode Last In First Out (LIFO) adalah metode penilaian persediaan yang terakhir masuk diasumsikan akan keluar atau dijual pertama kali. Metode ini memiliki konsep yang cukup sederhana namun sulit dilaksanakan. Pengaruh penggunaan metode $L I F O$ terhadap penentuan laba bersih usaha, jika harga cenderung naik maka laba perusahaan terlalu kecil atau sebaliknya.

Metode LIFO secara sistem fisik ditentukan dengan cara saldo fisik yang ada dikalikan harga pokok perunit barang yang masuk pada awal periode bila saldo fisik ternyata lebih besar dari barang yang masuk pada awal periode maka diambilkan dari harga pokok perunit yang masuk berikutnya. Sedangkan dengan sistem perpetual, setiap kali ada transaksi baik pembelian maupun penjualan dicatat dalam kartu persediaan.

\section{Metode Penelitian}

\section{Objek Penelitian}

Penelitian ini dilakukan untuk merancang suatu sistem informasi Persediaan material dengan metode perpetual FIFO berbasis web. Objek penelitian pada penyusunan tugas akhir ini adalah pada PT. Teknik Bina Mandiri Jl. Tarum Barat 1/83 Jababeka II Cikarang BaruBekasi 17550.

\section{Bahan Penelitian}

Bahan penelitian yang akan digunakan dalam penelitian ini yaitu seluruh data yang berkaitan dengan pemesanan dan cara pengelolaanya.
a) Faktur

Faktur adalah perhitungan penjualan dengan perhitungan pembayaran

b) Surat jalan

Surat jalan adalah surat penting keberadaannya dalam berbagai surat.

c) Invoice

Invoice adalah dokumen yang digunakan sebagai suatu bukti pembelian yang berisi jumlah pembayaran yang harus dibayar oleh pembeli.

\section{Alat Penelitian}

Alat penelitian yang digunakan dalam penelitian ini meliputi perangkat keras (hardware) dan perangkat lunak (software).

Tabel 1. Perangkat keras (hardware)

\begin{tabular}{|c|c|c|}
\hline No & Hardware & Deskripsi \\
\hline 1 & $\begin{array}{l}\text { Laptop (Sistem } \\
\text { Komputer) }\end{array}$ & $\begin{array}{lr}\text { Suatu alat yang terdiri } \\
\text { atas satu perangkat yang } \\
\text { memiliki papan tombol } \\
\text { (keyboard), } \\
\text { tampilan, layar } \\
\text { microprocessor dengan } \\
\text { spesifikasi processor }\end{array}$ \\
\hline & & $\begin{array}{l}\text { CPU Intel Core i5; } \\
\text { Memory 2048mb RAM } \\
\text { 4GB. }\end{array}$ \\
\hline 2 & Printer & $\begin{array}{l}\text { Alat yang digunakan } \\
\text { untuk mencetak tampilan } \\
\text { monitor ke kertas dan } \\
\text { informasi yang dicetak } \\
\text { dapat berupa teks dan } \\
\text { gambar. }\end{array}$ \\
\hline
\end{tabular}

Tabel 2. Perangkat lunak (software)

\begin{tabular}{|c|c|c|}
\hline No & Software & Deskripsi \\
\hline 1 & ХАMPP & Web server \\
\hline 2 & Ms Word & $\begin{array}{l}\text { Aplikasi pengolah } \\
\text { Bahasa pemrograman }\end{array}$ \\
\hline 3 & $\begin{array}{l}\text { Notepad } \\
++\end{array}$ & $\begin{array}{l}\text { Editing kode program atau } \\
\text { menulis kode program }\end{array}$ \\
\hline 4 & $\begin{array}{l}\text { Web } \\
\text { Browser }\end{array}$ & Mozilla Firefox \\
\hline 5 & StarUML & $\begin{array}{l}\text { Digunakan untuk membuat } \\
\text { dan perencanaan diagram } \\
\text { agar lebih terstruktur. }\end{array}$ \\
\hline
\end{tabular}




\section{Metode Pengembangan Sistem SDLC Waterfall}

Metode perancangan sistem yang digunakan dalam penelitian ini yaitu SDLC (System Development Life Cycle) waterfall meliputi beberapa tahap yaitu project planning phase, analysis phase, design phase, implementation phase, dan support phase seperti pada gambar 1 , berikut:

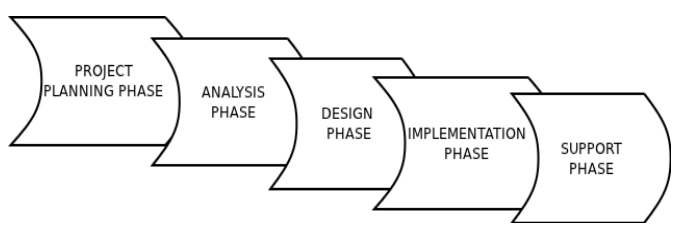

Gambar 1.The Waterfall Approach to The SDLC (Satzinger et al., 2007)

\section{Project Planing Phase}

Tahapan ini adalah tahap perencanaan, yang akan dilakukan adalah dengan mengidentifikasi masalah, pengumpulan data, menganalisis teori, pembuatan jadwal, mencari solusi dan mendefinisikan kebutuhan yang ditunjukan.

\section{Analysis Phase}

Analysis phase adalah tahap untuk memahami dan mendokumentasikan kebutuhan bisnis dan persyaratan pengolahan sistem baru. Dalam tahap analisis akan didefinisikan dalam bentuk grafis dari analysis sistem berjalan dan analisis sistem ajuan.

\section{Design Phase}

Pada tahap ini dilakukan analisis terhadap desain aplikasi untuk membuat palikasi menggunakan Object Oriented Design (OOD), seperti:

a) Desain Proses

Rancangan logika pemrosesan data yang akan disajikan menggunakan flowchart.

b) Desain Antarmuka

Rancangan tampilan msukan dan keluaran yang akan dioperasikan oleh user.

\section{Implementation Phase}

Implementation phase adalah tahap akhir untuk membangun, menguji dan menginstal sistem dimana sistem siap untuk dioperasikan.
Adapun hal utama yang harus diperhatikan dalam membuat implementasi yaitu :

a) Membangun perangkat lunak.

b) Verifikasi dan pengujian.

c) Mengkonversi data.

d) Melatih pengguna dan mendokumentasikan sistem.

e) Menginstal system

Setiap program mengalami pengujian secara pribadi untuk memastikan bahwa sistem yang telah dibuat bisa bebas dari kesalahan (bug), walaupun tidak menutup kemungkinan masih sedikit bug atau tidak $100 \%$ bebas dari bug, namun pengujian ini setidaknya bisa meminimalisir kesalahan yang terjadi.

Pengujian system dilakukan dengan dua tahap yaitu pengujian white box dan black box. Pengujian white box dilakukan pada pengecekan perancangan sistem, mengetahui cara kerja sistem secara internal agar operasi-operasi internal pada sistem sesuai dengan spesifikasi yang telah ditetapkan. Sedangkan pengujian black box yaitu suatu pendekatan untuk menguji apakah setiap fungsi didalam program dapat berjalan dengan benar. Berikut ini proses yang dilakukan dalam pengujian ini yaitu:

a) Fungsi-fungsi yang tidak benar, baik input maupun output

b) Kesalahan interface

c) Kesalahan dalam struktur data atau akses database

\section{Support Phase}

Support phase adalah tahap untuk menjaga sistem berjalan secara produktif awalnya dan selama bertahun-tahun seumur hidup sistem, melakukan pembaruan dan memelihara sistem setelah dijalankan. Adapun tiga hal utama yang harus dilakukan pada support phase yaitu memelihara sistem, meningkatkan sistem dan dukungan dari pengguna itu sendiri.

\section{Hasil dan Pembahasan}

\section{Project Planning Phase}

Pada tahap project planning phase dihasilkan rincian setiap aktifitas yang dilakukan 
selama penelitian, adapun hasil tahapan tersebut seperti dalam tabel berikut ini:

Tabel 3. Skenario Use Caseinput data user

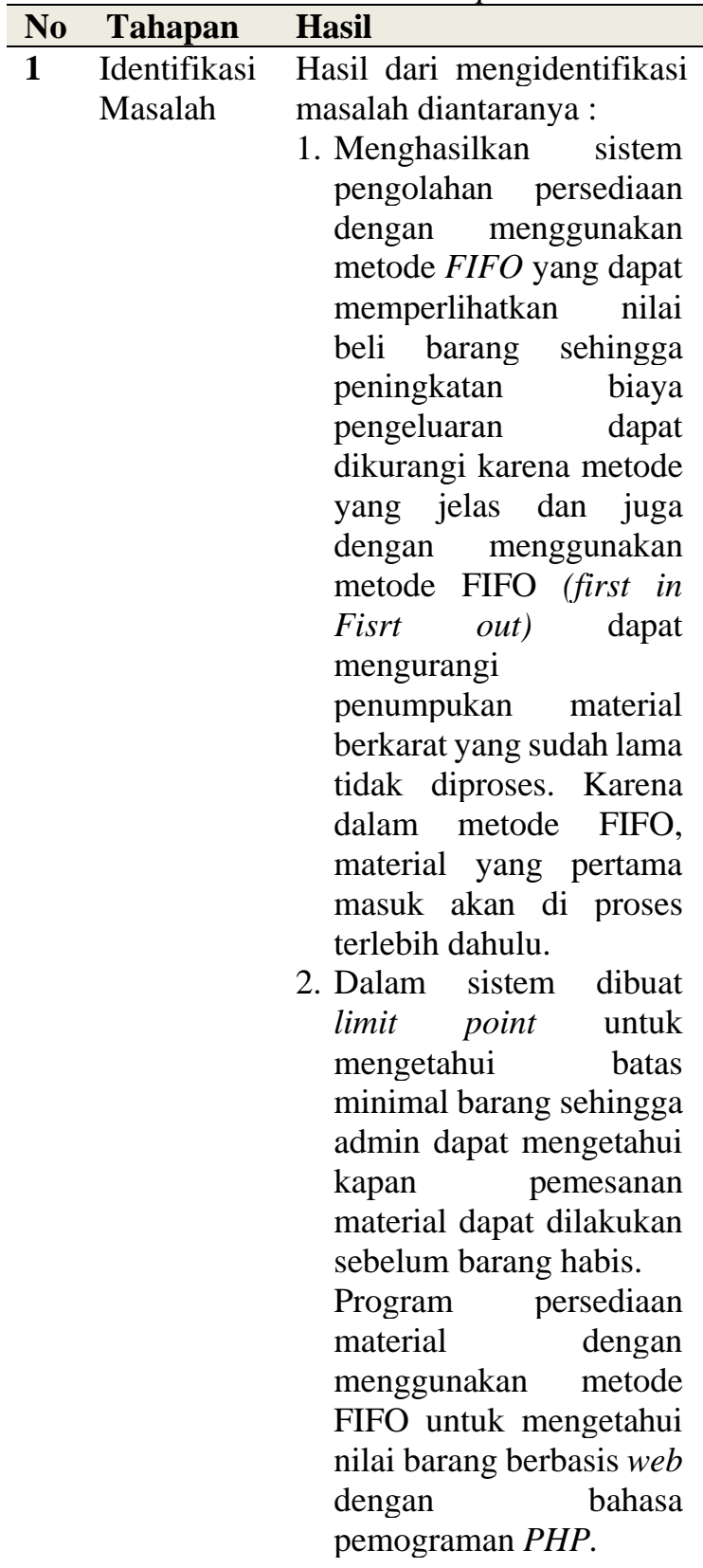

\begin{tabular}{lll}
\hline No & Tahapan & Hasil \\
\hline 2 & Pengumpu & 1. Dari interview, mendapat \\
& lan data & alur metode yang dipakai \\
& & di PT. Teknik Bina \\
& & Mandiri sehingga dpat \\
& menyimpulkan masalah \\
& apa yang terdapat dalam \\
& bagian persediaan. \\
& 2. Hasil dari riset/observasi \\
& dilapangan dapat \\
& mengidentifikasi atau \\
& gambaran untuk masalah \\
& di PT. Teknik Bina \\
& Mandiri.
\end{tabular}

3. Hasil dari metode studi pustaka yaitu dokumen faktur, surat jalan dan invoice, sebagai data yang digunakan untuk pencatatan persediaan dan sebagai penunjang pembuatan program persediaan material.

3 Menganali Analisis teori dari ebook sis teori tentang sistem informasi berbasis OOA (Object Oriented Approach) diperoleh tahapan analisis:

a) System Activities (Actor Description and Use Case Description, Use Case Diagram, Scenario Use Case).

b) Class Diagram (Class Definition, Class Relation).

c) Object Interaction (Sequence Diagram). Object Behavior (Activity Diagram).

Dari ebook tentang pendekatan sistem SDLC waterfall diperoleh tahapan pengembangan sistem :
a) Project planing phase
b) Analysis phase
c) Desain phase
d) Implementasi phase
e) Support phase

Dari jurnal penelitian dan buku yang diperoleh teori:

a) Sistem informasi

b) Data 


\begin{tabular}{lll}
\hline No Tahapan & Hasil & \\
\hline & c) & Pengolahan data secara \\
& & berkala \\
& d) & Pembuatan program \\
& & dengan OOP \\
& e) & PHP \\
& f) & MySQL \\
& g) & Web
\end{tabular}

4 Pembuatan Penelitian dilakukan di PT. jadwal Teknik Bina Mandiri Cikarang dari bulan februari-juli seperti yang dijelaskan pada tabel 1 .

5 Menentuk Membangun aplikasi sistem an solusi informasi yang akan digunakan untuk proses perhitungan persediaan material.

6 Mengident 1. Perangkat keras yang ifikasi Kebutuhan digunakan:
a. Laptop/komputer sebagai alat untuk menampilkan sebuah sistem.
b. Printer sebagai alat untuk mencetak tampilan monitor ke kertas.

2. Perangkat Lunak : Sistem operasi 64bit, notepad ++ , PHP, dan MYSQL, Browser, Bootstrap, CSS.

\section{Analysis Phase}

Analysis phase akan menjelaskan mengenai analisis sistem berjalan dan analisis sistem yang diajukan.

\subsection{Analisis Proses Persediaan Material Menggunakan Metode FIFO}

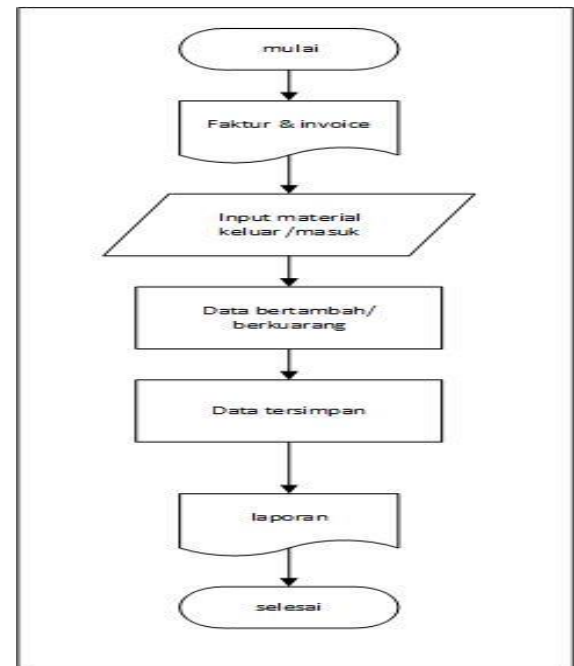

Gambar 2. Flowchart metode FIFO

Tabel 4. Descripsi flowchart.

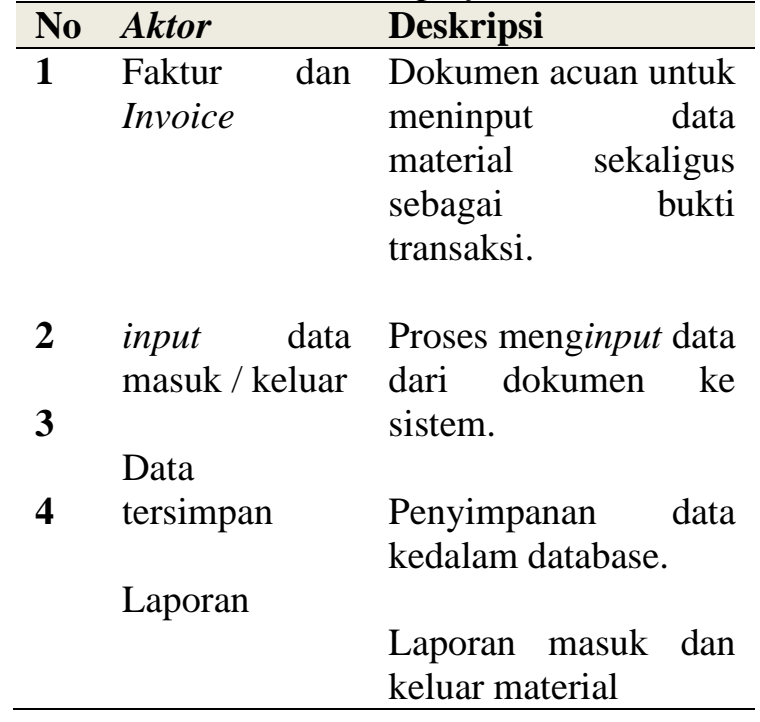

\subsection{Analisis Sistem}

Analisis sistem ajuan menggunakan analisis berbasis OOA (Object Oriented Approach) terdiri dari :

A. System Activities (Actor Description and Use Case Description, Use Case Diagram, Scenario Use Case)

1. Tabel Deskripsi Aktor

Berikut adalah definisi aktor yang ada di dalam sistem informasi persediaan material. Pada sistem ini terdiri dari 3 aktor, yang menggambarkan dalam tabel 5 berikut: 
Tabel 5. Definisi aktor

\begin{tabular}{|c|c|c|}
\hline No & Aktor & Deskripsi \\
\hline 1 & Bagian gudang & $\begin{array}{l}\text { Bagian persediaan } \\
\text { han-ya mempunyai } \\
\text { hak akses untuk } \\
\text { pencatatan keluar } \\
\text { masuk material. }\end{array}$ \\
\hline 2 & PPIC/Admin & $\begin{array}{l}\text { Merupakan } \\
\text { pengguna yang } \\
\text { memiliki hak akses } \\
\text { penuh terhadap } \\
\text { sistem informasi } \\
\text { per-sediaan } \\
\text { material }\end{array}$ \\
\hline & & $\begin{array}{l}\text { Merupakan } \\
\text { pengguna yang } \\
\text { memliki hak ak-ses } \\
\text { untuk melihat data- } \\
\text { data laporan yang } \\
\text { telah dikelola oleh } \\
\text { PPIC. }\end{array}$ \\
\hline
\end{tabular}

2. Tabel Deskripsi Use Case

Diagram use case mendeskripsikan sebuah interaksi antara satu atau lebih aktor dengan sistem yang akan dibuat. Diagram use case digunakan untuk mengetahui fungsi apa saja yang ada di dalam sebuah sistem dan siapa saja yang berhak menggunakan fungsi-fungsi tersebut.Use Case sistem tergambarkan dalam tabel berikut:

Tabel 6. Definisi Use Case

\begin{tabular}{lll}
\hline No & Actor & Deskripsi \\
\hline 1 & Input user & Merupakam ptoses \\
& & meny-impan data user, \\
& & meng-edit, menghapus \\
& & dan me-mperbarui data \\
& & user dal-am sistem.
\end{tabular}

2 Input material Merupakn proses menyi-mpan data material, me-ngedit, menghapus dan memperbarui data mate-rial, dan lihat

\section{Kelola} material masuk

5 Kelola material keluar

\section{Lihat laporan} material

\section{$7 \quad$ Login}

8 Logout data materi-al didalam sistem.

Merupakan proses meny-impan data pemasok, mengedit, menghapus dan memperbarui data pemasok, dan lihat data pemasok didalam sistem.

Merupakan proses meng-elola data material masuk yang meliputi tambah data, lihat data, mutkhir data, dan hapus data.

\section{Merupakan proses meng-elola data material masuk yang meliputi tambah data, lihat data, mutkhir data, dan hapus data.}

Merupakan proses melihat data laporan material masuk dan keluar kemu-dian di cetak.

Merupakan proses masuk kedalam sistem dengan memasukkan username dan password untuk mendapatkan hak akses terhadap sistem.

Merupakan proses keluar dari sistem.

\section{Use Case Diagram}

Use Case Diagram menggambarkan tentang tindakan apa saja yang dapat aktor (user) lakukan terhadap yang dibangun (fungsionalisme sistem).

Berikut ini adalah use case diagram yang terjadi pada sistem informasi persediaan material menggunakan metode 
FIFO di PT. Teknik Bina

Mandiri, Cikarang.

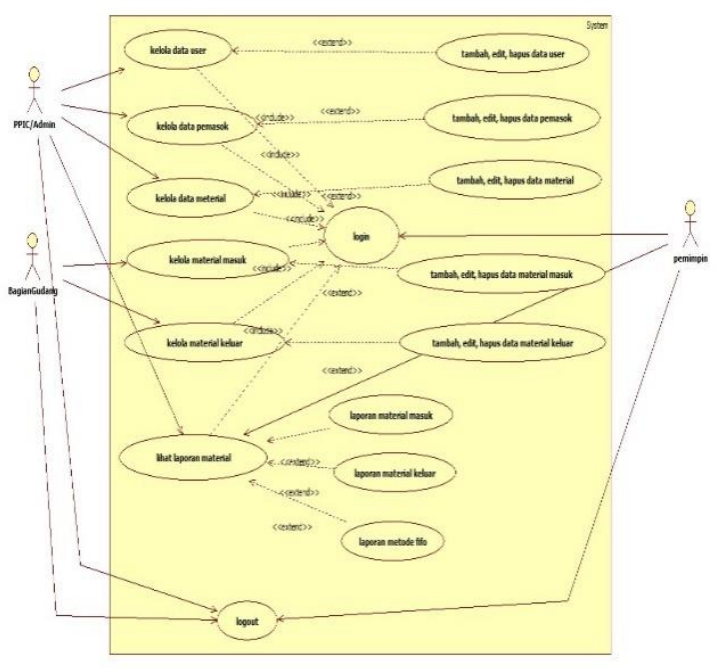

Gambar 3. Use Case Diagram

4. Class Diagram (Class Definition, Class Relation)

Class Diagram menampilkan class-class yang digunakan didalam sistem, dalam hal ini class diagram memberikan gambaran tentang sistem dan relasi yang terjadi di-dalamnya.

a. Class Definition

\begin{tabular}{|c|c|c|}
\hline No & Aktor & Deskripsi \\
\hline 1 & Users & $\begin{array}{l}\text { Merupakan kelas untuk } \\
\text { cek logindan logout. }\end{array}$ \\
\hline 2 & material & Merupakan kelas untuk \\
\hline 3 & pemasok & data material. \\
\hline 4 & mat_keluar & $\begin{array}{l}\text { Merupakan kelas untuk } \\
\text { data pemasok. }\end{array}$ \\
\hline 5 & mat_masuk & $\begin{array}{l}\text { Merupakan kelas untuk } \\
\text { data transaksi material }\end{array}$ \\
\hline \multirow[t]{4}{*}{6} & \multirow[t]{4}{*}{ laporan } & keluar. \\
\hline & & $\begin{array}{l}\text { Merupakan kelas untuk } \\
\text { data transaksi material } \\
\text { masuk. }\end{array}$ \\
\hline & & $\begin{array}{lr}\text { Merupakan } & \text { kelas untuk } \\
\text { menyimpan } & \text { laporan }\end{array}$ \\
\hline & & $\begin{array}{l}\text { material masuk dan } \\
\text { keluar. }\end{array}$ \\
\hline
\end{tabular}

b. Class Relation

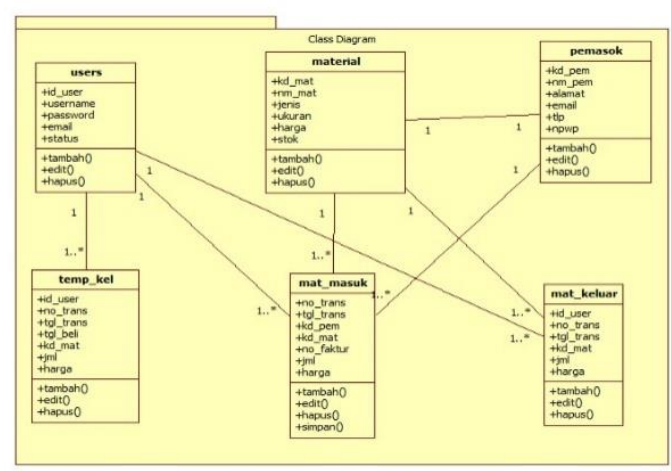

Gambar 4. Class Relation

5. Object Interaction (Sequence Diagram)

a. Sequnce Diagram Input Material Masuk

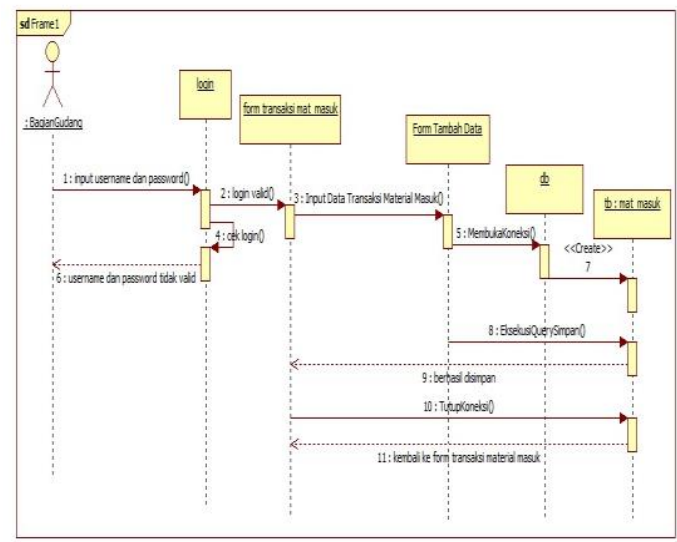

Gambar 5. Sequence Diagram Input Material Masuk

6. Object Behaviour (Activity Diagram)

Terdiri dari delapan activity yaitu, login, kelola user, kelola pemasok, kelola material, input material masuk, input material keluar, lihat laporan, logout. Activity Diagram Kelola Material Masuk 


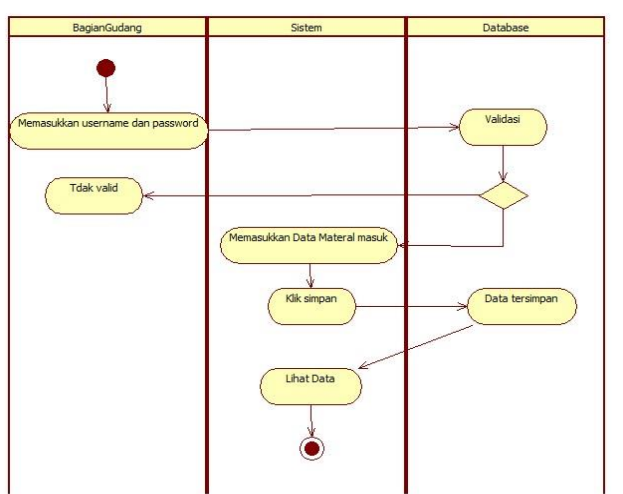

Gambar 6. Activity Diagram Input Material Masuk

\subsection{Desain Proses}

1. Desain Proses

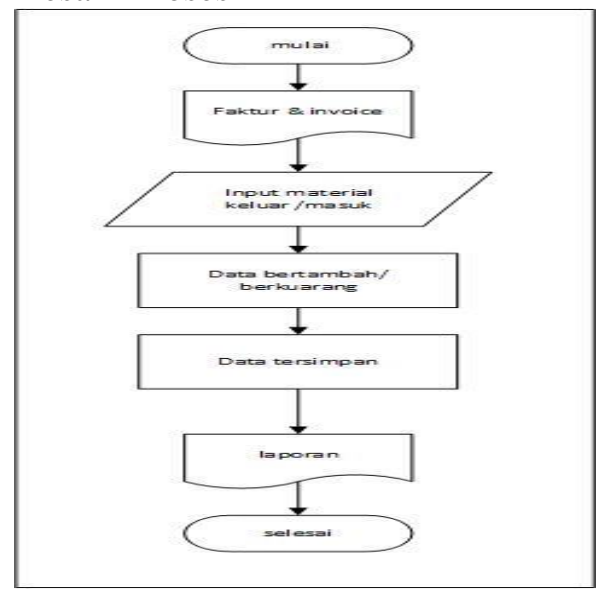

Gambar 7. Desain Proses

2. Desain Antarmuka

Tampilan Halaman Transaksi Material Masuk

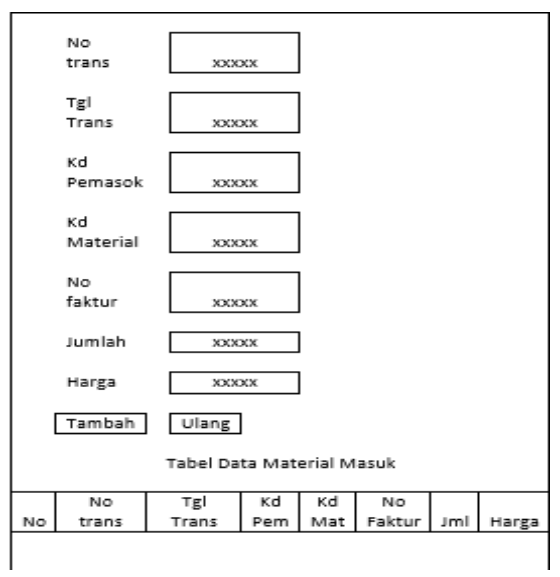

Gambar 8. Form Transaksi Material Masuk

\section{Kesimpulan dan Saran}

\section{Kesimpulan}

Berdasarkan penelitian yang telah dilakukan, maka dapat ditarik kesimpulan sebagai berikut :

1. Untuk mengatasi peningkatan biaya pengeluaran dan mengurangi material berkarat maka dibuat aplikasi persediaan material dengan menggunakan metode FIFO(first in first out). Jadi material pertama masuk akan diproses terlebih dahulu.

2. Dalam aplikasi ini dibuat peringatan minimum persediaan material untuk mengindari keterlambatan material.

3. Aplikasi dibuat berbasis web dengan bahasa pemograman php dan menggunakan Object Oriented Analysis(OOA).

\section{Saran}

Untuk mengembangkan aplikasi ini dimasa yang akan datang, disarankan untuk menambahkan hal-hal sebagai berikut:

1. Perlu adanya otomatisasi pemesanan material apabila material sudah berada dibatas minimum.

2. Perlu ditambahkan untuk laporan keuangan sehingga dapat menghitung pengeluaran kas perusahaan.

\section{Daftar Pustaka}

Azhar Susanto .2013. Sistem Informasi Akuntansi. Bandung : Lingga Jaya

Ely Suhayati dan Sri Dewi Anggadini. 2009. Akuntansi Keuangan Yogyakarta : Graha Ilmu

Fajar Junaedi EP, 2005. Panduan Lengkap Pemrograman HTML. Yogyakarta : Devisi Percetakan dan Penerbitan PD. Anindaya

Jogiyanto, H.M., 2009. Sistem Teknologi Informasi. Yogyakarta, Andi Offset, Yogyakarta Makalah Online ( 2016).

Peranginangin, Kasiman. 2006. Aplikasi WEB dengan PHP dan MySQL Andi Offset Yogyakarta 
Sutarman,2007. Membangun Aplikasi Web dengan PHP \& MySQL. Yogyakarta : GRAHA ILMU

Wing Wahyu Winarno.2006, Sistem Informasi Akuntansi, Edisi 2 Penerbit UPP STIM YKPN Yogyakarta

Chandra, Riny. 2017. Penerapan Sistem Pengendalian Manajemen Terhadap Kinerja Keuangan Pada PT. Indojaya Agri Nusa. Aceh : Unuversitas.

Fajar Junaedi EP, 2005. Panduan Lengkap Pemrograman HTML. Yogyakarta :

Devisi Percetakan dan Penerbitan PD. Anindaya http://elib.unikom.ac.id

Indonesian Jurnal On Networking and Security (IJNS) ISSN: 2302-5700

Jhonsen, WEB DESIGNER untuk PEMULA. Jakarta : Elex Media Komputindo Kelompok Gramedia, Anggota IKAPI, 2004

Jogiyanto, H.M., 2009. Sistem Teknologi Informasi. Yogyakarta, Andi Offset, Yogyakarta

Mangkulo, Hengky Alexander. 2004. Membuat Aplikasi Database denganDelphi 8.0. Surabaya : C.V ANDI Offset

Peranginangin, Kasiman. Aplikasi WEB dengan PHP dan MySQL Yogyakarta : Andi, 2006

Puspitasari, Eki dan Purnama, Bambang Eka dan Sukadi. 2013. Sistem Informasi Pengolahan Raport Siswa Pada SMP Negeri 3 Kebon Agung. Pacitan :

Samudra Volume : 8, Nomor : 1 Januari 2017

Sutarman,2007. Membangun Aplikasi Web dengan PHP \& MySQL. Yogyakarta : GRAHA ILMU

Tjiptono, F, 2008. Strategi Pemasaran. Edisi Ketiga, Andi, Yogyakarta 